\title{
APPLICATION OF PROJECT-BASED CHANGE MANAGEMENT IN CONSTRUCTION: A CASE STUDY
}

\author{
Chun-Sung CHEN ${ }^{\mathrm{a}}$, Yu-Kun TSUI ${ }^{\mathrm{b}}$, Ren-Jye DZENG ${ }^{\mathrm{b}}$, Wei-Chih WANG $^{\mathrm{b}}$ \\ a Department of Applied Geomatics, Ching Yun University, No. 229, Chien-Hsin Rd., Jung-Li, Taiwan \\ ${ }^{b}$ Department of Civil Engineering, National Chiao Tung University, No. 1001, University Road, \\ Hsin-Chu, Taiwan
}

Received 28 Feb 2012; accepted 21 Jun 2012

\begin{abstract}
Real-time information is vital to enhance dynamic control and management via information sharing and analysis in order to reduce construction conflicts and project delays. However, most construction project management programs are ineffective for project prompt responses, especially with respect to change management. This work presents a novel construction project management system called the web project-based change management (WPCM) system. The WPCM system responds to changes in information efficiently in order to facilitate change management among project participants (e.g. general contractor, suppliers, and subcontractors) in a construction project environment. Capable of increasing information sharing in construction change management, web-based technology can also provide cost savings via the Internet. A case study involving a commercial building project in Taiwan demonstrates the effectiveness of both the proposed WPCM system and information sharing in change control during the construction phase. In addition to increasing the efficiency of change control and management for a general contractor, as well as dynamic project tracking and management, the proposed system enables subcontractors and suppliers to access and manage the change information timely. Future work should implement the system functions comprehensively and apply the system to additional projects more strictly for further verification of its reliability.
\end{abstract}

Keywords: change management, information system, web-based system, construction management.

\section{Introduction}

Taiwan undertakes numerous civil and building construction projects annually, as evidenced by an average annual budget for public construction projects of around $\$ 17,400$ million US dollars in the recent decade (PCC 2012). Following Taiwan's accession to the World Trade Organization (WTO) in 1998, most domestic large scale engineering and construction projects are procured internationally according to the Taiwan Government's Procurement Act (PCC 1998). Despite the project management and controls uniformly adopted in large-scale construction projects, unforeseen changes often occur when the projects have time-constrained requirements. In particular, many high-tech plant construction projects in Taiwan incur serious problems involving unforeseen changes during the construction phase. Such problems are generally viewed as having an adverse impact on project performance, despite the pervasive use of construction management approaches in Taiwan's construction industry.

Construction activities often involve many complex uncertainties. Change is of priority concern in construction project management (Zou, Lee 2008; Zhao et al. 2010). Unpredictable changes in construction projects can significantly alter contractual terms with respect to time and costs (Tiong 1990; Ibbs 1997; Ibbs et al. 1998, 2001). Changes can be attributed to a combination of factors (Pritchett, Pound 1996; Sun, Meng 2009). Changes are unavoidable in construction projects, and effective control of such changes is essential to project success (Zou, Lee 2009). Any additions, deletions, or revisions to project goals or scope are considered to be changes, regardless of whether they increase or decrease project costs or the schedule (Ibbs et al. 2001). Change management, an approach for managing and organizing projects, is increasingly adopted in the construction industry. Project development generally comprises several phases, requiring a diverse array of specialized services and numerous participants. Adequately controlling and managing construction change are extremely challenging tasks. Real-time monitoring and control of construction project changes are necessary for completing projects within a budget and on schedule. Web-based information management solutions have facilitated information sharing among project participants. Online project communication and management allows contractors, subcontractors, and suppliers to provide project participants with

Corresponding author: Wei-Chih Wang

E-mail:weichih@mail.nctu.edu.tw 
advanced project-based change information. Contractors and subcontractors generally require access to change information in order to control and manage construction changes and related activities. However, the general contractor, subcontractors, and suppliers in most construction projects in Taiwan typically use telephones and faxes to communicate with each other. Communication regarding project changes among these project participants is thus inefficient.

Information technology is important to managing construction changes, especially by improving change coordination among project participants (Sun, Oza 2010). Utilizing web technology to facilitate information sharing in construction project management is of priority concern. Moreover, integrating information technologies such as web technology (e.g. portal solutions) can increase the effectiveness of the information flow and flexibility in construction project management. A web-based system is a flexible and cost-effective means of gathering, filtering, managing, and sharing information to support construction management (Molenaar, Songer 2001; Ng et al. 2003; Nitithamyong, Skibniewski 2004; Chan, Leung 2004; Kong et al. 2004; Cheung et al. 2004; Lee et al. 2006b; Motawa et al. 2007; Forcada et al. 2010; Siao, Lin 2012). However, most project management programs are infeasible for responding to and controlling changes for facilitating change management.

Taiwan has the following problems involving construction change management: most commercial project management programs, including Primavera Project Planner and Microsoft Project, have only a few functionalities that support change management; rework problems regarding data entry by project participants occur during change information communication and exchanges; most project participants fail to track most recent changes in information; and most project management programs for web-based use are difficult to use. Despite the extensive use of project management programs, few systems and platforms assist project participants in managing and sharing project-based changes in information. Therefore, this work focuses on providing basic functionalities for change management systems and increasing interface user friendliness for project participants.

Information sharing in a web environment can facilitate tracking and controlling changes in construction projects. Changes in information sharing in construction projects follow the process of collecting changes in data from project participants. Reliable information and data acquisition influence the change in information flows between a general contractor and project participants. Communication problems normally arise when project participants have either different versions of the same program or entirely different programs.

This work focuses on the following objectives: develop a project-based change management system with a simple design interface; increase the efficiency of change information collection and information sharing, based on use of web technologies; enable project participants to receive real-time change-related information in order to enhance decision-making capabilities in change management and control; and, support project managers and participants in monitoring and controlling construction change processes dynamically. Furthermore, a case study involving implementation of the WPCM system in a commerce building in Taiwan demonstrates the effectiveness of the proposed system in terms of information sharing in project teams.

\section{Literature review}

The frequency of errors and changes significantly contributes to uncertainty in construction projects (Hanna et al. 1999a, b, 2004; Lee et al. 1999, 2003, 2006a). Construction changes normally occur in any project phase due to various sources, which significantly impact a project (Karim, Adeli 1999; Al-Sedairy 2001; Motawa et al. 2007; Senaratne, Sexton 2011). Project changes are of priority concern in construction projects (Ming et al. 2004).

Project changes have numerous definitions. Park (2002) referred to project change as work status, processes, or methods that differ from the original plan. Love et al. (2002) stated that changes during a project's development may have significant and often unpredictable effects on its organization and management. Arain et al. (2004) defined a change as any modification to the contractual agreement provided by the contractors or owners. Isaac and Navon (2008) asserted that changes are largely owing to factors such as project delays, overhead costs and differences in quality from the agreed upon requirements. Sun and Meng (2009) defined change as an alteration to design, building work, project program or other project areas caused by modifications to preexisting conditions, assumptions or requirements in construction projects.

Integrally related to all internal and external factors of a project that cause project changes, change management strives to forecast possible changes, identify changes having already occurred, plan preventive impacts, and coordinate changes across an entire project (Voropajev 1998; Singh, Shoura 2006). Change management resolves problems when changes occur in a project or minimize changes that may disrupt project progress (Zhao et al. 2010). In addition to addressing the impact of changes, effective change management should also examine project costs, time and quality considerations. Inconsistent management of changes may disrupt the project in many ways (Motawa et al. 2007). Additionally, the inability of a formal change management process to address changes effectively may lead to contractual disputes and, ultimately, project failure (Hwang, Low 2012).

Numerous change management studies in the construction industry have addressed some of the following areas: developing a change management system to manage design change in a collaborative environment 
(Mokhtar et al. 1998); developing an object-oriented information model for schedule, cost optimization, and change order management (Karim, Adeli 1999); developing an information model to facilitate design management of design changes (Hegazy et al. 2001); developing a project change management system to promote a balanced change culture, recognize change, evaluate change, implement change, and continuously improve based on previous experiences (Ibbs et al. 2001); developing a change order management system to manage change problems in construction projects (Charoenngam et al. 2003); developing a core system for quality and change management (Lee et al. 2006a); designing a change management toolkit for construction projects by using a change dependency framework, change prediction, and workflow tools (Sun et al. 2006); developing a strategic framework for change management (Price, Chahal 2006); proposing causal linkages to explain the interactions among changes, disruptions, productivity losses, and formation of parties when changes occur (Ibbs et al. 2007); devising an integrated change management system to represent the major decisions required to implement changes and simulate the iterative cycles of concurrent design and construction resulting from unanticipated changes and their subsequent impacts (Motawa et al. 2007); elucidating the relationships between project characteristics (e.g. project types and complexity) and implementing best practices of project change management (Zou, Lee 2009); analysing the frequency of change orders (Anastasopoulos et al. 2010); designing a change prediction system to generate detailed information about changes (Zhao et al. 2010); identifying the causes/reasons of changes (Alnuaimi et al. 2010; Enshassi et al. 2010; Shehab, Cano 2010; Brochner, Badenfelt 2011); and assessing the status, importance and impact of change management implementation in the Singapore construction industry (Hwang, Low 2012).

Despite many articles and system developments in academic and professional literature, general contractors, subcontractors, and suppliers lack systematic approaches and information platforms to monitor and manage change events during the construction phase. This work attempts to fill this gap in the literature.

\section{Research methodology}

Research methodology of this work includes a literature review, workshops, observation by participation, and 20 expert interviews. Also, a case study evaluates the effectiveness of change management practices based on the proposed system. Participants in the case study include a general contractor and 13 subcontractors. In the case study, various forms (e.g. change record sheets and change control sheets) are developed for construction change management. Additionally, during the case study, researchers and representatives of the involved case participants discuss the results, problems, limitations and suggestions for proposed change processes. Roles and communications are also deemed appropriate or advised to be further developed. Notably, data for the case study are collected in 2010.

The literature review sheds light on the roles of project participants in change management, along with the data required to develop an adequate questionnaire. The questionnaire includes the basic profile of the participating companies and respondents. The next section discusses the requirements for construction change management in practice with respect to change type, change roles, and change management phases during implementation of change management. Section 5 (case study) also includes questions that not only reflect the requirement of construction change management in practice, but also explore how the proposed WPCM system impacts functionality of the system, use of the system and capability of the system in terms of the percentage of improvements made. With a total of 20 questions, the questionnaire is sent to the case participants, with 13 complete sets returned. Based on the obtained data, analyses are performed, with those results discussed in Section 5.2 (Test results).

The ability of project participants to manage unforeseen changes largely determines construction project success. Thoroughly elucidating unforeseen changes in construction management is essential for effective change management. Efficacy of overall change management practice in different project types can vary widely, depending on the project nature, industrial types, project complexity, project size, contractual terms and expertise level of project participants (Hwang, Low 2012). Project participants must effectively respond to unforeseen changes to minimize potentially adverse impacts on a project (Ibbs et al. 2001). However, implementing such changes is complex and not always successful, largely owing to poor communication or underestimation of the amount of retraining required (Price, Chahal 2006). Therefore, this work presents a novel project-based change management system to manage unforeseen changes in a construction project.

\section{Proposed system}

Based on a literature review and interviews, the proposed change management system defines change as either active or passive. Table 1 describes these two changes. The change management process has been extensively studied. Ibbs et al. (2001) suggested four phases of change management: recognize changes, evaluate changes, implement changes, and learn from previous experiences. Motawa et al. (2007) later proposed four phases of change management: start up, identify and evaluate, approve and propagate, and post changes. In this work, the proposed project-based change management system consists of the following five phases of change: identification, confirmation, notification, implementation, and closure. Figure 1 provides further details, while Table 2 describes each change management phase.

Previous studies define change roles in various ways. These change roles are agent, owner, manager, team, 
Table 1. Changes in change management

\begin{tabular}{ll}
\hline Change type & \multicolumn{1}{c}{ Definition } \\
\hline Active change & $\begin{array}{l}\text { A project member defines change as active to achieve special purposes } \\
\text { (e.g. shortening project duration or reducing costs). Relevant members are notified } \\
\text { when the change arises. }\end{array}$ \\
\hline & $\begin{array}{l}\text { A project member defines change as passive or reactive when unexpected events } \\
\text { (e.g. changes of fire-protection regulations, changes of specifications or unavailability } \\
\text { of owner's budgets) force adjustments in project conditions. Relevant members are } \\
\text { notified when the change arises. }\end{array}$ \\
\hline
\end{tabular}

Table 2. Definition of change management phases

\begin{tabular}{ll}
\hline Phase & \multicolumn{1}{c}{ Definition } \\
\hline Change identification & An actual condition differs from the originally planned one. \\
\hline Change confirmation & Relevant project stakeholders verify a change. \\
\hline Change notification & All relevant project stakeholders are notified of a change. \\
\hline Change implementation & Relevant project stakeholders record and execute a change. \\
\hline Change closure & $\begin{array}{l}\text { A change process is finalized and its change results are sent to relevant project } \\
\text { stakeholders. }\end{array}$ \\
\hline
\end{tabular}

Table 3. Roles played by project participants in managing change

\begin{tabular}{ll}
\hline Project participants & Definition \\
\hline Change initiator & Individual who first raised a change event in the project environment \\
\hline Change stakeholder & Individual who has direct or indirect relationships with the consequence of a change event \\
\hline Change coordinator & Individual who must coordinate with the implementation of a change event \\
\hline Change manager & Individual who monitors/controls the development of a change event \\
\hline Change approver & Individual who approves changes during change management \\
\hline
\end{tabular}

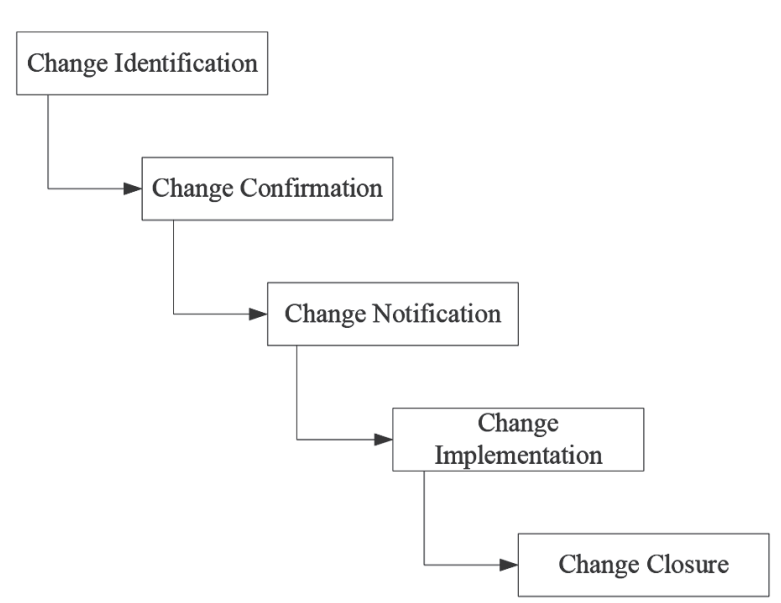

Fig. 1. Five phases of change management

expert, and management consultant (Lippet et al. 1958; Beckhard, Pritchard 1992; Lee, Krayer 2003; Newton 2007; Klewes, Langen 2008; Stummer, Zuchi 2010). In this work, the proposed project-based change roles consist of the following five roles: initiator, stakeholder, coordinator, manager, and approver. Table 3 lists the various roles played by project participants in managing changes in a construction project.

Figure 2 displays the framework of the proposed WPCM system. Figure 3 presents the steps of monitoring changes in the system. The first step of the system identifies the change. The entire change progress is analysed through the system when the change event is identified. The second step of the system confirms the change. After the participant confirms the change, the change is diagnosed through the system. The system contains information regarding the historical records of changes and detailed information of changes, change breakdown structure, and change control sheet. This information assists the construction management team in monitoring and managing changes. The change implementation phase focuses mainly on maintaining a complete record of changes.

The third step of the system is to notify the change. Therefore, an environment that allows relevant participants to communicate with each another must be created. In this stage, each related project participant is encouraged to access and identify potential changes. Identifying changes before they occur can help project participants to manage changes better and earlier during the change 


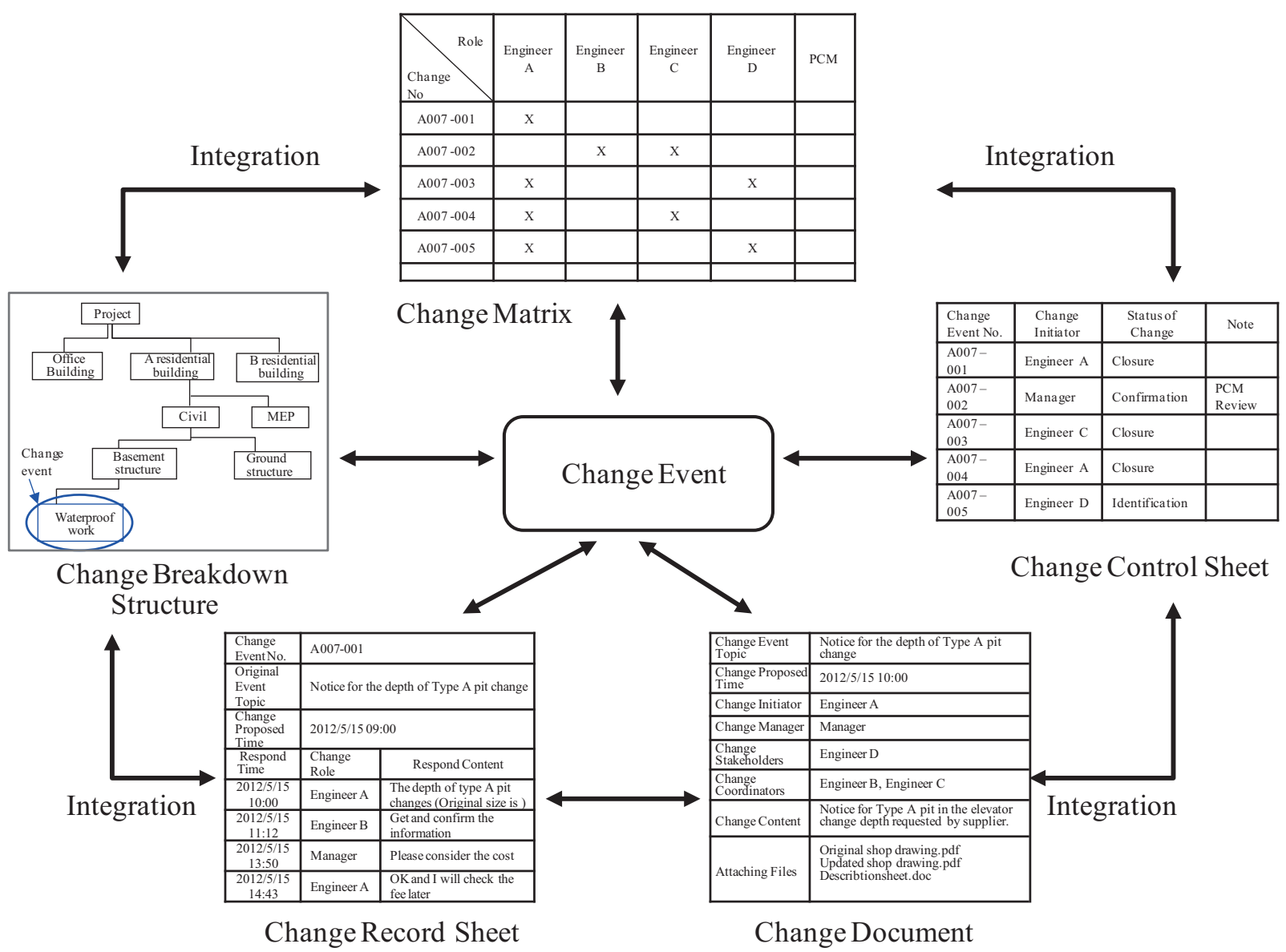

Fig. 2. Proposed system

monitoring. Moreover, the system provides structured information regarding the changes that facilitate effective communication between project participants.

Following the notification phase, the participant communicates the details of the change with all affected parties. Documenting the changes implemented is an integral feature of the notification phase. During the implementation phase, tracking changes is essential to controlling the changes. The change management system eventually leads the decision makers to the suggested controls for changes and assists them in selecting the most appropriate decisions. This system can provide project managers with timely information for decision making on how to respond to changes.

\section{System implementation}

Web-based technology is an effective means of improving change-related information control in construction change management. Information sharing eliminates the need for different offices to regenerate or re-enter the same information. Eliminating redundant data entries also helps maintain data consistency by reducing the likelihood of human error. The proposed WPCM system adopts various technologies for information sharing. Portals are ideal platforms for sharing information in web-based project management systems. When a portal is used, all information in a project database can be acquired via a web interface. The portal also provides authentication and access control mechanisms, allowing project participants to access information based on their privileges.

\subsection{System architecture}

The proposed WPCM system stores and classifies all data by using activity-based units. Theoretically, the functions of WPCM should be made available to all project participants via a portal, which also acts as a realtime and on-line communication channel for project participants. All authorized participants can operate the web project management controls based on data shared via the proposed system. When the data are updated on the server side, e-mails should be sent automatically from a server to the project manager of the general contractor, as well as to participants involved in the relevant activity.

The proposed system provides a personalized gateway that allows each participant to access relevant information provided by other project participants. Moreover, the system provides a solution involving a single and unified database, linked to all functional systems with 


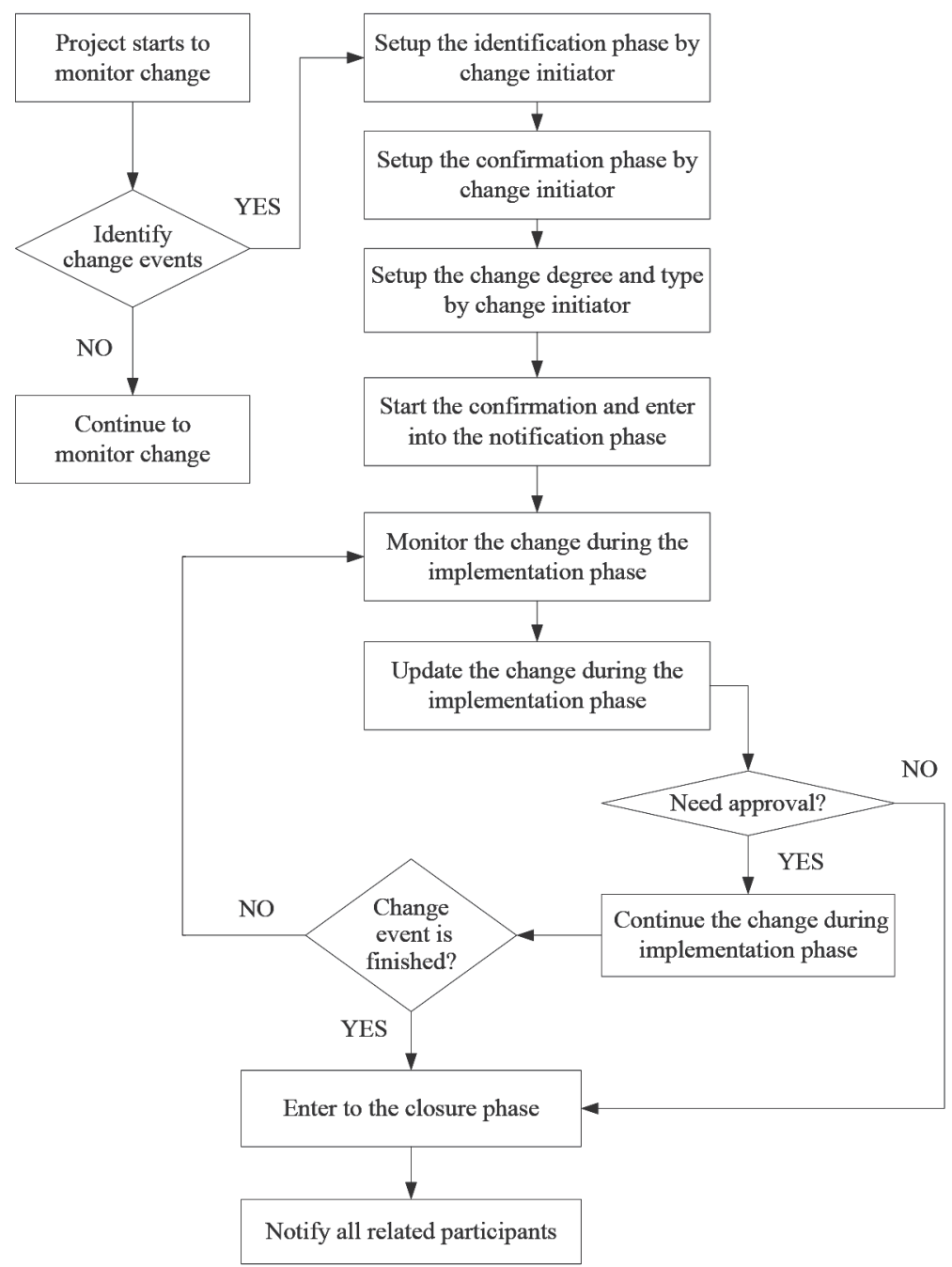

Fig. 3. Steps of monitoring changes in the proposed system

different levels of access to information, depending on the role of the user, both within organizations and across organizations and other project participants.

Within the WPCM system, all project-related information acquired by project participants is hosted in a system database. Depending on access privileges, project participants can access all or a portion of this information via a portal. The WPCM system is based on Microsoft's Windows 2000 operating system with Internet Information Server (IIS) functioning as the web server. The prototype is developed using Java Server Pages (JSP), which are easily incorporated with HTML and JavaScript technologies, to transform an Internet browser into a user-friendly interface. Microsoft's SQL Server 2003 acts as the database for information storage. The server of the WPCM system comprises three distinct layer types (i.e. presentation, application and database layers), each with their own responsibilities. Figure 4 schematically depicts the proposed system architecture.

The presentation layer defines administration and end-user interfaces appropriate for the work of the end user. Users can access necessary information via web

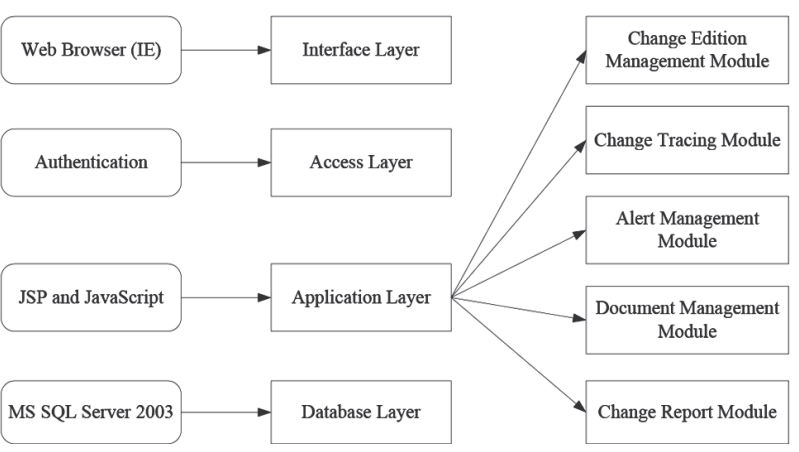

Fig. 4. WPCM system architecture

browsers, including Microsoft Internet Explorer and Firefox. Moreover, administrators can manage information via a web browser and a separate server interface. The application layer defines various applications for accumulating and managing information. These applications enable system security, information sharing, project control and monitoring and system administration. The database layer includes SQL Server 2003. 


\subsection{System feature modules}

This section introduces the functionality requirements of the proposed project-based change management system based on several interviews with general contractors and subcontractors. Five system modules are developed to comply with related requirements.

\subsubsection{Change edit module}

This change edit module allows project participants to edit change information of a change event and submit a new change event. Responsible project participants can also update the progress or condition of change-related works and events. Additionally, this module serves as an access mechanism that prevents unauthorized users from entering and/or retrieving project change information. During the progress of change management, an invited participant or responsible engineer can enter the system and edit or respond effectively via comments to a change issue or event. Moreover, as change-related information or reports required by different project participants vary, the general contractor is assigned the most accessible authority. This module identifies and verifies the authorities of individuals before they enter data or transmit information.

\subsubsection{Change history module}

The change history module generates a complete history of an entire change process. Participants can enter planned schedule data, update actual schedule data, and compare work completed with the planned via the proposed system. After subcontractors and suppliers have entered schedule-related data, the general contractor can $\log$ into the system to monitor the latest schedule information. Most uploaded files are converted automatically into pdf documents. This module allows users to download electronic documents. Additionally, this module stores change-related files, including contracts, drawings, and specifications. This module also has a "search" function, allowing for easy identification and retrieval of required information in dynamic construction environments. This module allows participants to manage and organize files in a central location, as well as track a complete history of an entire change process.

\subsubsection{Change tracking module}

This change monitoring module enables project participants to monitor change events. Project participants can also track the progress or delivery conditions of critical change events. This module provides an easy access option, allowing participants to monitor all information regarding the change status of selected change events. Additionally, unscheduled change events are monitored as denoted by a reddish colour to alert project participants. This module allows change-related participants to become oriented on the latest condition status of change events for advanced decision analysis and making. This module, a novel approach to information sharing, is unavailable in existing project management programs.

\subsubsection{Alert setup module}

This alert setup module is designed to help changerelated participants to determine how the most recent delayed or changed events impact the project status. Most importantly, the recording of crucial dates related to the notification, delay, and change stages allows for project participants to easily establish liability when delays occur. Additionally, this module provides a convenient access and push function that helps engineers to identify and respond to situations before they occur. Moreover, this module allows participants responsible for or concerned with the change events to subscribe and monitor the status of change events when the relevant project participants are notified about the alert by e-mail if change events are updated.

\subsubsection{Online change report module}

The online change report module is an easily accessed environment in which users can analyse all changerelated information based on user requirements. All results can be displayed in the web environment or extracted using commercial software such as Microsoft Word and Excel. This module includes functions for analysing change information (e.g. simple bar charts and statistical charts). Records maintained by the contractor, subcontractors, and suppliers can be extracted and summarized into useful reports. Furthermore, this module allows the extraction of all change record sheets into a web html or PDF file format for downloading.

\section{Case study}

\subsection{Description}

The case study is a commercial building project located in northern Taiwan. This project lasted approximately 13 months. Initially, three subcontractors and five suppliers were involved in construction. The general contractor initially used Microsoft Project 2003 to coordinate the entire project. Only two of the three subcontractors used Microsoft Project 2003 to manage the project. The other participants used fax or e-mails for communication. Following discussions, the general contractor and project participants attempted to use the proposed WPCM system to manage the project changes in a collaborate manner.

Take an example of change event for illustration. The component supplier held discussions with the general contractor since some components were not manufactured according to the original schedule. During the change identification and confirmation phases, the supplier first announces that the delivery of some components will be late. Once this change event is identified by the supplier (i.e. change initiator) and confirmed by the general contractor, project participants start to monitor the information of the change event. Additionally, all participants are notified of the change event and then obtain the initial change documents, change control sheet, and change record sheet from the proposed system. 
During the change implementation phase, the WPCM system updates and records all change-related information in change documents, change control sheets, and change record sheets provided by change participants (i.e. change stakeholders and coordinators). Before assembly, components are manufactured and delivered to the construction site. The component manufacturer uploads the most recent information and drawings to the system. The system then identifies all change-related roles based on updated change information. Next, the project manager of the general contractor verifies the change process via the change matrix table. The participants also access the system to identify the change status when the construction drawings of components are released and updated. Moreover, onsite engineers (i.e. change stakeholders) are instructed to update the status of the change event for component construction drawings. Following delivery of components to the site, onsite engineers and subcontractors enter inspection results, edit descriptions, and input updated information into the WPCM system. The system sends an alarm message automatically to the project manager at the head office, requesting that managers confirm the updated information regarding the assembly status of components. Furthermore, the supplier may log into the system and check the number of components that have been delivered to the construction site.

In the change closure phase, the general contractor's onsite engineer (i.e. change manager) verifies the component quantity and quality and, then, records assessment results in the WPCM system. Finally, the change approver makes the final confirmation of the change process. At this phase, authorized project participants can assess the finalized records of the change event using the system.

This case study has 53 change events. Figure 5 illustrates the screenshots taken from the proposed WPCM system in the case study. Notably, Chinese is the language used in the WPCM system. The screenshot shown in Figure 5 has been translated into English for presentation purposes.

\subsection{Test results}

Test results indicate that the WPCM system is a simple platform that supports project participants in managing changes. During the case study, the system was installed in the general contractor's main server. A user's guide workshop and two system workshops were held to teach participants on how to use the system.

Selected case participators used the system and, then, project teams provided feedback via a questionnaire. Case participants included two subcontractor project managers with 10 years of experience; two supplier project managers and five senior engineers with 10 years of experience; three senior engineers with 15 years of experience as a general contractor; and a project manager with 20 years of experience as a general contractor.

Based on comparisons with the conventional way, system users graded the system functions, system use, and system capability on a five-point Likert scale, respectively. The Likert scale ranges from 1 for "strongly disagree" to 5 for "strongly agree". Table 4 summarizes the system test results.

Questionnaire results indicate an improved efficiency in change control and management. A general contractor satisfaction score of $83 \%$ indicates that the system can monitor the change-based information in a real-time environment. The WPCM system records the complete records of project-based change management from project participants. All users are allowed to access the most recent change information and obtain a brief report directly from the Internet. With assistance of the system, change management is enhanced with effective change documentation of analytical reports.

The subcontractors and suppliers rated satisfaction at $86 \%$, indicating that the WPCM system is adequately designed and user friendly. Users can track the most recent situations regarding all information changed directly and indirectly. Subcontractors and suppliers can select an activity and check changes in other activities. Most subcontractors

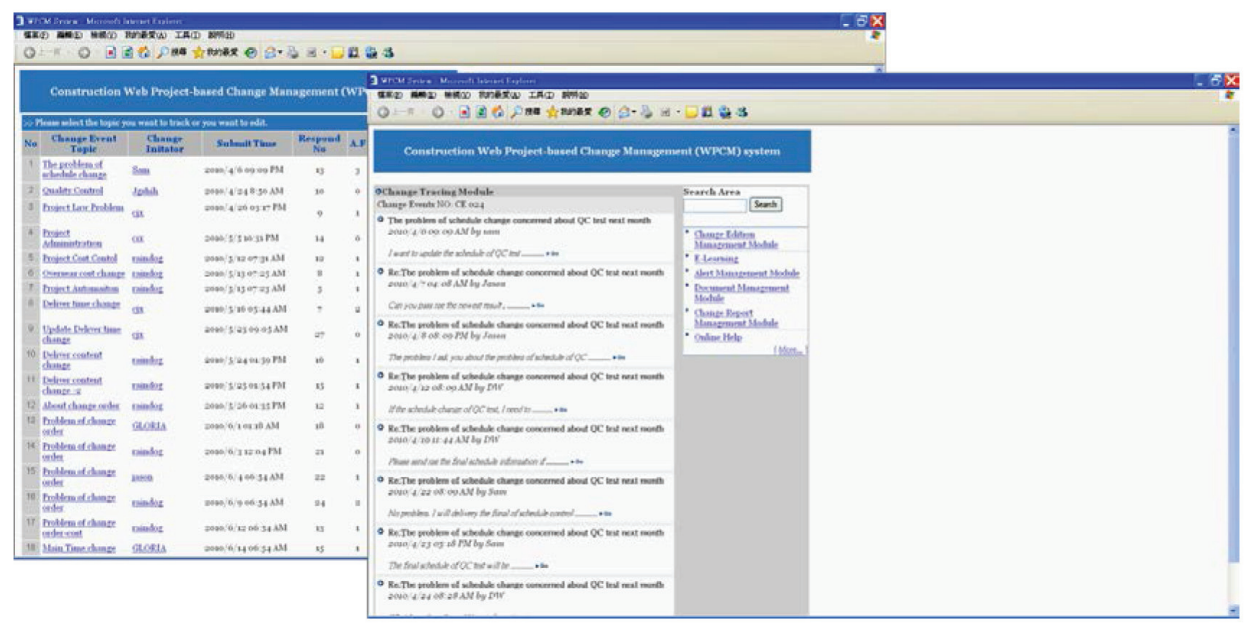

Fig. 5. Screenshot taken from the WPCM system in the case study 
Table 4. System evaluation results

\begin{tabular}{lc}
\hline System functions & Mean score \\
\hline Ease of sharing change information & 4.6 \\
\hline Reliability & 4.4 \\
\hline Applicability to construction industry & 4.5 \\
\hline System use & Mean score \\
\hline Ease of use & 4.5 \\
\hline User interface & 4.6 \\
\hline Information sufficiency & 3.9 \\
\hline System usefulness & 4.2 \\
\hline System capability & Mean score \\
\hline Reduce rework & 4.4 \\
\hline Reduce unnecessary costs & 3.9 \\
\hline $\begin{array}{l}\text { Reduce the percentage of recurring } \\
\text { mistakes }\end{array}$ & 4.5 \\
\hline Ease in identifying changes & 4.6 \\
\hline $\begin{array}{l}\text { Improve the avoidance of conflict } \\
\text { problems }\end{array}$ & 3.7 \\
\hline \begin{tabular}{l} 
Enhance the monitoring of changes \\
\hline Enhance the search for change records
\end{tabular} & 4.4 \\
\hline $\begin{array}{l}\text { Improve change-related information } \\
\text { sharing }\end{array}$ & 4.3 \\
\hline
\end{tabular}

Note: the mean score is estimated based on respondents' feedback on five-scale questionnaire: 1 (strongly disagree), 2, 3, 4 and 5 (strongly agree).

and suppliers agree that the WPCM system increases the efficiency of change-related information sharing among participants, thereby assisting project managers and participants in monitoring the change progress.

Figure 6 displays the percentage for various categories of change in the case study. Restated, changes related to schedules, shop drawings, construction methods/ sequences, and participants (e.g. subcontractors or engineers), and others (e.g. quantity variations and owner's requirements) are about $43 \%, 21 \%, 14 \%, 8 \%$, and $14 \%$, respectively.
Figure 7 illustrates the main difficulties of using the proposed WPCM system in the case study. The problem of having insufficient time for editing change information is around $34 \%$. Also, the problem of not receiving adequate support from top management is up to $20 \%$. The problem of insufficient support of detailed change information sharing approaches $18 \%$. The problem of not providing appropriate change in information editing environment in the jobsite accounts for $18 \%$. Moreover, the problem of lacking motivation to exchange change-related information reaches $7 \%$, while the problem to receive support from other project parties reaches $3 \%$.

\subsection{Limitations and barriers to implementation}

Based on user feedback, primary barriers to implementing the WPCM system were identified as follows: insufficiently updated information related to various changes; substantial amounts of time and assistance needed for senior engineers to edit and update change-related information; dissatisfaction among most users with the high disconnection rate and slow Internet speed; and unwillingness of participants to share change-related information.

Despite its contributions, the proposed system has certain limitations. First, project-based change monitoring approach may be infeasible for some project participants

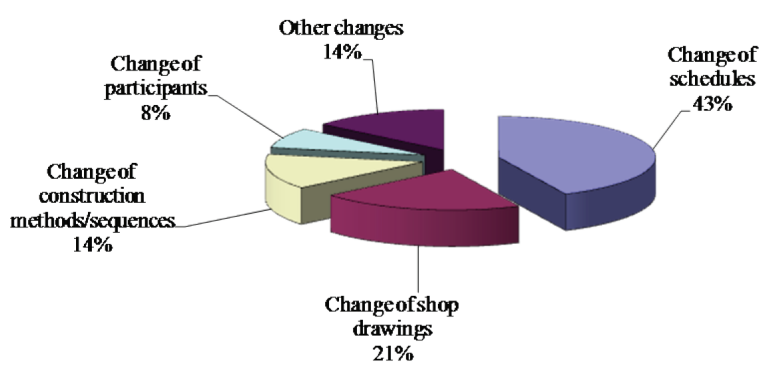

Fig. 6. Percentage for various categories of change in the case study

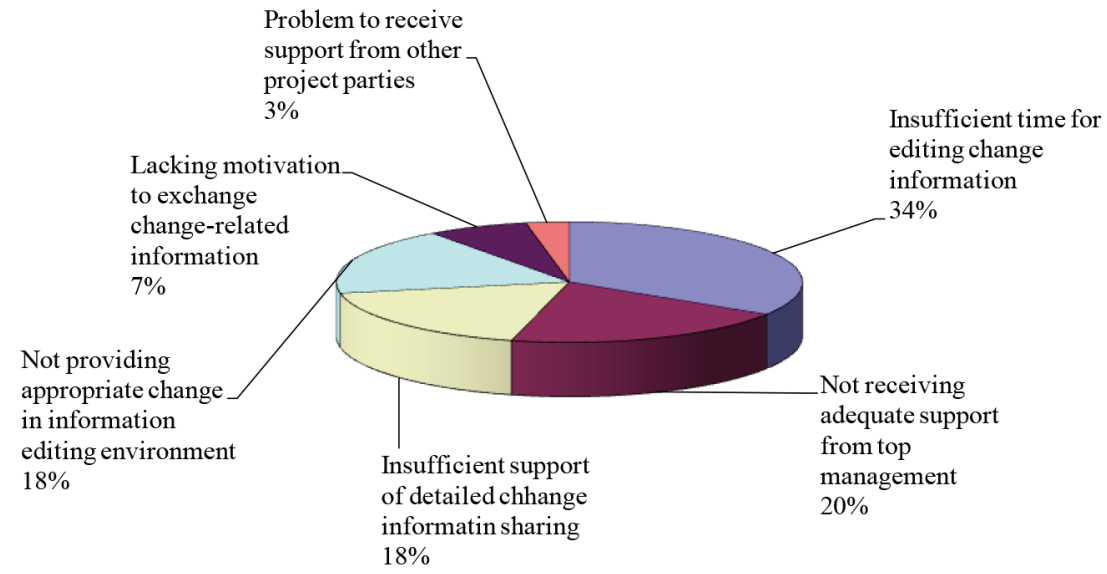

Fig. 7. Main difficulties of using the WPCM system in the case study 
who are not familiar with using web-based applications. Additionally, some engineers and managers expressed concern that they lack sufficient time and assistance to edit and update the change-related information. Another obstacle is that not all involved subcontractors and suppliers have the same attitude towards use of change management in the proposed WPCM system. Developing a system that satisfies all involved parties depends on an advanced analysis of the perspectives of different parties. Future research must address how such an analysis of perspectives can be integrated into project-based change management.

Additionally, the proposed WPCM system is inapplicable for use on a construction site directly. Namely, onsite engineers could modify their changes only when they returned to the site office. Most onsite engineers agreed that editing their changes at the jobsite by using a smart phone or notebook in a Wi-Fi or $3 \mathrm{G}$ environment would be convenient.

\section{Conclusions}

Even the most carefully planned project undergoes unforeseen schedule changes due to various factors. Cost and delay-related problems in a project can be minimized if a systematic approach is available to manage changes in construction projects. In practice, disregarded or late responses to changes often occur during construction, frequently incurring project disruptions. This work develops a novel projectbased change management system to manage unforeseen changes in a construction project. The system is a useful means of handling change, both from the perspective of a project and on the event level. In this work, change management consists of five phases: identification, confirmation, notification, implementation, and closure. Furthermore, change management includes five main roles: initiator, stakeholder, coordinator, manager, and approver.

The proposed WPCM system can overcome consistency problems in change-related information, allowing for participants to integrate change processes seamlessly. Integrating Internet-based technologies and dynamic real-time information from all project participants helps managers and engineers to monitor all construction change-related progress. We recommend the following directions for future research:

- Several functions of the proposed WPCM system should be refined and some functions (e.g. an online change collaborative function) should be developed. Future work should implement the system functions comprehensively.

- Despite the ability of the case study project to display the potential advantages of the proposed system, some of the practitioners involved in this investigation suggested that the execution process of this case study should be improved and be more rigorous under a fully-developed system. Thus, additional in-depth case studies of applying the fullyimplemented system to other projects are required for further verification.
- Project partners are normally concerned with confidential information kept outside their companies. Using dedicated servers should provide a relatively safe means of keeping all information in the absence of security services.

- The data/information that must be shared among project participants should be identified in advance. This requirement is owing to that data/information to be shared often differs in projects. Thus, the flexibility of incorporating various data/information types should be provided.

- Incorporating mobile devices with the proposed system should be useful because site engineers can revise change-related information directly on a mobile device without returning to the site office.

- The general contractor must implement the construction change management system actively because most participants (e.g. subcontractors and suppliers) are subject to pay additional costs of using the proposed system. Thus, a rewards incentive policy can be implemented in the contract between the general contractor and subcontractors/ suppliers.

\section{Acknowledgement}

The authors would like to thank the anonymous reviewers for their careful evaluation and invaluable comments. The K-T Construction Inc. is commended for its assistance in the system design and interviews, as well as the experts and engineers of the project owner for providing useful data, valuable information, and helpful comments during system design and development. Ted Knoy is appreciated for his editorial assistance.

\section{References}

Alnuaimi, A. S.; Taha, R. A.; Al Mohsin, M.; Al-Harthi, A. S. 2010. Causes, effects, benefits, and remedies of change orders on public construction projects in Oman, Journal of Construction Engineering and Management 136(5): 615-622. http://dx.doi.org/10.1061/(ASCE)CO.1943-7862.0000154

Al-Sedairy, S. T. 2001. A change management model for Saudi construction industry, International Journal of Project Management 19(3): 161-169.

http://dx.doi.org/10.1016/S0263-7863(99)00067-8

Anastasopoulos, P. C.; Labi, S.; Bhargava, A.; Bordat, C.; Mannering, F. L. 2010. Frequency of change orders in highway construction using alternate count-data modeling methods, Journal of Construction Engineering and Management 136(8): 886-893. http://dx.doi.org/10.1061/(ASCE)CO.1943-7862.0000198

Arain, F. M.; Assaf, S.; Low, S. P. 2004. Causes of discrepancies between design and construction, Architectural Science Review 47(3): 237-249. http://dx.doi.org/10.1080/00038628.2000.9697530

Beckhard, R.; Pritchard, W. 1992. Changing the essence: the art of creating and leading fundamental change in organizations. San Francisco: Jossey Bass. 105 p.

Brochner, J.; Badenfelt, U. 2011. Changes and change management in construction and IT projects, Automation in Construction 20(7): 767-775. http://dx.doi.org/10.1016/j.autcon.2011.01.001 
Chan, S. L.; Leung, N. N. 2004. Prototype web-based construction project management system, Journal of Construction Engineering and Management 130(6): 935-943.

http://dx.doi.org/10.1061/(ASCE)0733-9364(2004)130:6(935)

Charoenngam, C.; Coquince, S. T.; Hadikusumo, B. H. W. 2003. Web-based application for managing change orders in construction projects, Construction Innovation 3(4): 197-215. http://dx.doi.org/10.1108/14714170310814936

Cheung, S. O.; Suen, C. H.; Cheung, K. W. 2004. PPMS: a web-based construction project performance monitoring systems, Automation in Construction 13(2): 361-376. http://dx.doi.org/10.1016/j.autcon.2003.12.001

Enshassi, A.; Arain, F.; Al-Raee, S. 2010. Causes of variation orders in construction projects in the Gaza Strip, Journal of Civil Engineering and Management 16(4): 540-551. http://dx.doi.org/10.3846/jcem.2010.60

Forcada, N.; Casals, M.; Fuertes, A.; Gangolells, M.; Roca, X. 2010. A web-based system for sharing and disseminating research results: the underground construction case study, Automation in Construction 19(4): 458-474.

http://dx.doi.org/10.1016/j.autcon.2009.12.018

Hanna, A. S.; Camlic, R.; Peterson, P.; Lee, M. J. 2004. Cumulative effect of project changes for electrical and mechanical construction, Journal of Construction Engineering and Management 130(6): 762-771.

http://dx.doi.org/10.1061/(ASCE)0733-9364(2004)130:6(762)

Hanna, A. S.; Russell, J. S.; Vandenberg, P. J. 1999a. The impact of change orders on mechanical construction labour efficiency, Construction Management and Economics 17(6): 721-730. http://dx.doi.org/10.1080/014461999371060

Hanna, A. S.; Russell, J. S.; Nordheim, E. V.; Bruggink, M. J. 1999b. Impact of change orders on labor efficiency for electrical construction, Journal of Construction Engineering and Management 125(4): 224-232.

http://dx.doi.org/10.1061/(ASCE)0733-9364(1999)125:4(224)

Hegazy, T.; Zaneldin, E.; Grierson, D. 2001. Improving design coordination for building projects. I: information model, Journal of Construction Engineering and Management 127(4): 322-329.

http://dx.doi.org/10.1061/(ASCE)0733-9364(2001)127:4(322)

Hwang, B. G.; Low, L. K. 2012. Construction project change management in Singapore: status, importance and impact, International Journal of Project Management 30(7): 817826. http://dx.doi.org/10.1016/j.ijproman.2011.11.001

Ibbs, C. W.; Lee, S.; Li, M. 1998. Fast-tracking's impact on project change, Project Management Journal 29(4): 35-41.

Ibbs, C. W. 1997. Quantitative impacts of project change: size issues, Journal of Construction Engineering and Management 123(3): 308-311.

http://dx.doi.org/10.1061/(ASCE)0733-9364(1997)123:3(308)

Ibbs, C. W.; Nguyen, L. D.; Lee, S. 2007. Quantified impacts of project change, Journal of Professional Issues in Engineering Education and Practice 133(1): 45-52.

http://dx.doi.org/10.1061/(ASCE)1052-3928(2007)133:1(45)

Ibbs, C. W.; Wong, C.; Kwak, H. 2001. Project change management system, Journal of Management in Engineering 17(3): 159-165.

http://dx.doi.org/10.1061/(ASCE)0742-597X(2001)17:3(159)

Isaac, S.; Navon, R. 2008. Feasibility study of an automated tool for identifying the implications of changes in construction projects, Journal of Construction Engineering and Management 134(2): 139-145.

http://dx.doi.org/10.1061/(ASCE)0733-9364(2008)134:2(139)

Karim, A.; Adeli, H. 1999. CONSCOM: An OO construction scheduling and change management system, Journal of Construction Engineering and Management 125(5): 368-376.

http://dx.doi.org/10.1061/(ASCE)0733-9364(1999)125:5(368)
Klewes, J.; Langen, R. 2008. Change 2.0: beyond organisational transformation. Berlin: Springer. $188 \mathrm{p}$. http://dx.doi.org/10.1007/978-3-540-77495-2

Kong, C. W.; Li, H.; Hung, P. L.; Shi, W. Z.; Daniel, C. L.; Skibniewski, M. 2004. Enabling information sharing between E-commerce systems for construction material procurement, Automation in Construction 15(1): 84-97.

Lee, S.; Peña-Mora, F.; Park, M. 2003. Dynamic quality and change management framework for concurrent design and construction, in ASCE Construction Research Congress, 19-21 March 2003, Honolulu, Hawaii.

Lee, S.; Peña-Mora, F.; Park, M. 2006a. Dynamic planning and control methodology for strategic and operational construction project management, Automation in Construction 15(1): 84-97. http://dx.doi.org/10.1016/j.autcon.2005.02.008

Lee, S.; Peña-Mora, F.; Park, M. 2006b. Web-enabled system dynamics model for error and change management on concurrent design and construction projects, Journal of Computing in Civil Engineering 20(4): 290-300.

http://dx.doi.org/10.1061/(ASCE)0887-3801(2006)20:4(290)

Lee, S.; Peña-Mora, F; Park, M. 1999. Quality and change management model for large scale concurrent design and construction projects, Journal of Construction Engineering and Management 131(8): 368-376.

Lee, W. W.; Krayer, J. K. 2003. Organizing change. San Francisco: John Wiley and Sons. $272 \mathrm{p}$.

Lippitt, R.; Watson, J.; Westley, B. 1958. The dynamics of planned change. Harcourt: Brace and World. $312 \mathrm{p}$.

Love, P. E.; Holt, G. D.; Shen, L. Y.; Li, H.; Irani, Z. 2002. Using systems dynamics to better understand change and rework in construction project management systems, International Journal of Project Management 20(6): 425436. http://dx.doi.org/10.1016/S0263-7863(01)00039-4

Ming, S.; Sexton, M.; Aouad, G.; Fleming, A.; Senaratne, S.; Anumba, C. 2004. Industrial report: managing changes in construction projects [online], [cited 27 April 2012]. Available from Internet:

http://www.bne.uwe.ac.uk/cprc/ publications/med.pdf

Mokhtar, A.; Bedard, C.; Fazio, P. 1998. Information model for managing design changes in a collaborative environment, Journal of Computing in Civil Engineering 12(2): 82-92.

http://dx.doi.org/10.1061/(ASCE)0887-3801(1998)12:2(82)

Molenaar, K. R.; Songer, A. D. 2001. Web-based decision support systems: case study in project delivery, Journal of Computing in Civil Engineering 15(4): 259-267.

http://dx.doi.org/10.1061/(ASCE)0887-3801(2001)15:4(259)

Motawa, I. A.; Anumba, C. J.; Lee, S.; Peña-Mora, F. 2007. An integrated system for change management in construction, Automation in Construction 16(3): 368-377. http://dx.doi.org/10.1016/j.autcon.2006.07.005

Newton, R. 2007. Managing change step by step. Harlow: Prentice Hall. 243 p.

Ng, S. T.; Palaneeswaran, E.; Kumaraswamy, M. M. 2003. Web-based centralized multiclient cooperative contractor registration system, Journal of Computing in Civil Engineering 17(1): 28-37.

http://dx.doi.org/10.1061/(ASCE)0887-3801(2003)17:1(28)

Nitithamyong, P.; Skibniewski, M. J. 2004. Web-based construction project management systems: how to make them successful?, Automation in Construction 13(2): 491-506. http://dx.doi.org/10.1016/j.autcon.2004.02.003

Park, M. 2002. Dynamic change management for fast-tracking construction projects [online], [cited 27 April 2012]. Available from Internet: http://fire.nist.gov/bfrlpubs/build02/art129.html

PCC. 1998. Government Procurement Act, Public Construction Commission, Executive Yuan, Taiwan [online], [cited 18 May 
2012]. Available from Internet: http://www.pcc.gov.tw/eng/index.php?code $=$ list\&flag $=$ detail\&ids $=33 \&$ article_id $=22$

PCC. 2012. Public Construction Commission, Executive Yuan, Taiwan [online], [cited May 18, 2012]. Available from Internet:

http://www.pcc.gov.tw/pccap2/TMPLfronted/ChtIndex.o?site=002

Price, A. D. F.; Chahal, K. 2006. A strategic framework for change management, Construction Management and Economics 24(6): 237-251. http://dx.doi.org/10.1080/01446190500227011

Pritchett, P.; Pound, R. 1996. The employee handbook for organizational change. Atlanta: Pritchett and Hull Associates. 40 p.

Senaratne S.; Sexton, M. 2011. Managing change in construction projects: a knowledge-based approach. London: Wiley-Blackwell. 200 p.

Shehab, T.; Cano, F. 2010. Change orders in the heavy civil construction industry: causes and management, International Conference on Management Science and Engineering 1: 18-20.

Siao, F. C.; Lin, Y. C. 2012. Enhancing construction interface management using multilevel interface matrix approach, Journal of Civil Engineering and Management 18(1): 133-144. http://dx.doi.org/10.3846/13923730.2012.657368

Singh, A.; Shoura, M. 2006. A life cycle evaluation of change in an engineering organization: a case study, International Journal of Project Management 24(4): 337-348. http://dx.doi.org/10.1016/j.ijproman.2005.11.001

Stummer, M.; Zuchi, D. 2010. Developing roles in change processes - a case study from a public sector organization, International Journal of Project Management 28(4): 384-394.

http://dx.doi.org/10.1016/j.ijproman.2010.01.009
Sun, M.; Meng, X. 2009. Taxonomy for change causes and effects in construction projects, International Journal of Project Management 27(6): 560-572. http://dx.doi.org/10.1016/j.ijproman.2008.10.005

Sun, M.; Oza, T. 2010. User survey: the benefits of an online collaborative contract change management system, Electronic Journal of Information Technology in Construction 15: 258-268.

Sun, M.; Fleming, A.; Senaratne, S.; Motawa, I.; Yeoh, M. L. 2006. A change management toolkit for construction projects, Architectural Engineering and Design Management 2(4): 261-271.

Tiong, R. 1990. Effective controls for large scale construction projects, Project Management Journal 11(1): 32-42.

Voropajev, V. 1998. Change management - a key integrative function of PM in transition economies, International Journal of Project Management 16(1): 15-19. http://dx.doi.org/10.1016/S0263-7863(97)00010-0

Zhao, Z. Y.; Lv, Q. L.; Zou, J.; Zillante, G. 2010. Prediction system for change management in construction projects, Journal of Construction Engineering and Management 136(6): 659-669. http://dx.doi.org/10.1061/(ASCE)CO.1943-7862.0000168

Zou, Y.; Lee, S. H. 2008. The impacts of change management practices on project change cost performance, Construction Management and Economics 26(4): 387-393. http://dx.doi.org/10.1080/01446190801918714

Zou, Y.; Lee, S. H. 2009. Implementation of project change management best practice in different project environments, Canadian Journal of Civil Engineering 36(3): 439-448.

http://dx.doi.org/10.1139/L08-138

Chun-Sung CHEN. He is a Professor in the Department of Applied Geomatics at Ching Yun University, Taiwan. His research interests include geodesy, geophysical exploration and construction quality control.

Yu-Kun TSUI. He is a PhD candidate in the Department of Civil Engineering at National Chiao Tung University, Taiwan. He is also the CEO of K-T Construction Inc in Hsin-Chu, Taiwan. His specialization is in the construction management of high-tech facilities. His research interests include construction change management and construction bidding.

Ren-Jye DZENG. He is a Professor in the Department of Civil Engineering at National Chiao Tung University, Taiwan. He is also the CEO of the Smart Living Technologies Integration Center. He received his PhD degree from the University of Michigan, Ann Arbor in 1995. His research interests include construction automation, artificial intelligence, and the accelerator and brain EEG applications for construction safety.

Wei-Chih WANG. He is a Professor in the Department of Civil Engineering at National Chiao Tung University, Taiwan. He received his $\mathrm{PhD}$ degree from the University of California at Berkeley in 1996. He is a member of the Construction Management Association of Taiwan. His research interests include construction procurement, high-tech facility project management, and construction simulation. 